\title{
COMPOSIÇÃO BROMATOLÓGICA DE FRUTOS NATIVOS DA REGIÃO DO VALE DO JURUÁ, ACRE
}

\author{
Jessé de França Silva ${ }^{1}$, Fabrício Rivelli Mesquita ${ }^{2}$, William Ferreira Alves ${ }^{2}$, Maria \\ Lucinara Moreira Chaves ${ }^{3}$, Adauto Pena Junior ${ }^{4}$ \\ ${ }^{1}$ Estudante de graduação em Engenharia Agronômica, UFAC - Campus Floresta \\ Estrada do Canela Fina, km 12, Gleba Formoso, Lote 245, Colônia São Francisco, \\ CEP: 69980-00 - Cruzeiro do Sul, jessefranca12@gmail.com \\ ${ }^{2}$ Professor Dr. Adjunto da UFAC - Campus Floresta, Acre; \\ ${ }^{3}$ Bacharel em Ciências Biológicas, UFAC - Campus Floresta \\ ${ }^{4}$ Licenciado em Educação Física, FAGAMMON
}

Recebido em: 22/09/2018 - Aprovado em: 23/11/2018 - Publicado em: 03/12/2018

DOI: 10.18677/EnciBio 2018B21

\begin{abstract}
Em razão da grande variedade de frutos na Amazônia Ocidental, trabalhos que se dedicam a decifrar o valor nutricional, permitem agregar valor à esses frutos. 0 estudo objetivou caracterizar a composição físico-química do Abiu (Pouteria caimito [Ruiz\&Pav.] Radlk.), Biribá (Rollinia mucosa [Jacq.]) Baill) e o Cupuaçu (Theobroma grandiflorum), frutos nativos da região do Vale do Juruá-Acre. O trabalho foi realizado no laboratório de Bromatologia Universidade Federal do Acre - Campus Floresta. Foi utilizado o delineamento experimental inteiramente casualizado, com três tratamentos (frutos) e quatro repetições. Foram quantificadas as variáveis matéria seca, matéria mineral, proteína bruta, extrato etéreo, fibra bruta e carboidratos totais ou extrativos não-nitrogenados. Os resultados de cada variável foram os seguintes: matéria seca $(11,81 \%$ a $15,25 \%)$, matéria mineral $(0,63 \%$ a $1,05 \%)$, proteína bruta $(4,36 \%$ a $7,03 \%)$, extrato etéreo $(2,70 \%$ a $3,57 \%)$, fibra bruta $(3,15 \%$ a $4,79 \%)$ e carboidratos totais ou extrativos não nitrogenados $(83,95 \%$ a $88,62 \%$ ). A polpa dos frutos analisados apresentaram composição bromatológica distinta, de modo que os resultados obtidos são relevantes para agregar valor aos frutos na região do Vale do Juruá, permitindo subsidiar estratégias para 0 desenvolvimento e uso de produtos obtidos a partir dessas espécies frutíferas.
\end{abstract}

RESUMO

PALAVRAS-CHAVE: Amazônia; bromatologia; nutrição.

\section{PHYSICO-CHEMICAL CHARACTERIZATION OF FRUITS NATIVE TO THE REGION OF THE VALLEY OF THE JURUÁ, ACRE}

\begin{abstract}
Because of the wide variety of fruits in the Western Amazon, jobs that are dedicated to decipher the nutritional value, allow you to add value to these fruits. The study aimed to characterize the physico-chemical composition of the Abiu (Pouteria caimito [Ruiz\&Pav.] Radlk.), Biribá (Rollinia mucosa [Jacq.]) Baill) and the cupuaçu (Theobroma grandiflorum), fruits native to the region of the valley of the Juruá-Acre. The work was carried out in the laboratory of bromatology Acre Federal University -
\end{abstract}


Campus Forest. The experimental design used was completely randomized experimental design, with three treatments (fruits) and four replications. Were quantified the variables dry matter, mineral matter, crude protein, ether extract, crude fiber and total carbohydrates or nitrogenous non-wood extractives. The results for each variable were the following: dry matter $(11.81 \%$ to $15.25 \%)$, mineral matter $(0.63 \%$ to $1.05 \%)$, crude protein $(4.36 \%$ to $7.03 \%)$, ether extract $(2.70 \%$ to $3.57 \%)$, crude fiber (3.15\% to $4.79 \%)$ and total carbohydrates or nitrogenous extractives not (83.95\% and $88.62 \%)$. The fruits analyzed showed different compositions, so that each fruit has its intrinsic characteristic. The results obtained are relevant relevant to the nutritional status of these fruits.

KEYWORDS: Amazon; bromatology; nutrition.

\section{INTRODUÇÃO}

O Brasil destaca-se por ser o terceiro maior produtor de frutos no mundo, sendo responsável por cerca de $6 \%$ da produção mundial (ANDRIGUETO et al., 2014). A fruticultura amazônica, entretanto, representa menos de 0,2 \% desse total (ROMERO, 2009), apesar do fato da Amazônia Brasileira possuir aproximadamente 220 plantas produtoras de frutos comestíveis, que ainda não têm o seu potencial das explorado pelos agricultores. Após o falecimento de Chico Mendes e consequente exposição da Amazônia à mídia mundial, as frutas nativas ganharam destaque, as quais anteriormente tinham consumo local e sazonal. Como resultado, as frutas Amazônicas ganharam mercado interno e externo (HOMMA, 2016).

O abieiro (Pouteria caimito (Ruiz \& Pav.) Radlk.), espécie amazônica e pertencente à família das sapotáceas, é uma árvore de 5 a 6 metros de altura, com folhas pecioladas, glabras e os frutos possuem forma ovóide ou esférica com casca amarela e lisa, às vezes amarela com estrias verdes, com massa entre 300 e 1000 gramas, polpa translúcida, branca ou amarela, mucilaginosa, doce ou insípida, contendo de 1 a 5 sementes grandes e lisas de cor preta e com grande aceitação popular, utilizado em sua maioria na forma in natura (DONADIO, 1992). O fruto apesar de presente em grande parte da região amazônica ainda não é explorado comercialmente em maior escala. Para minimizar os impactos do desmatamento e a extinção, de espécies, em regiões tropicais, são necessários conhecimentos mínimos, podendo-se ressaltar um dos grandes problemas encontrados, nos inventários realizados em floresta tropicais, a identificação correta das plântulas, já que mesmo os botânicos mais experientes não conseguem identificar, com exatidão, o banco de plântulas (SILVA et al., 2016).

O biribá (Rollinia mucosa [Jacq.] Baill) é uma planta originária do Brasil sendo um representante da família Annonaceae. Sua polpa varia de esbranquiçada a creme, possuindo muitas sementes de cor escura; além de um aroma agradável, podendo pesar mais de um quilograma. O consumo no Brasil das anonáceas vem crescendo a cada dia e a oferta interna ainda é insuficiente. A necessidade da disposição de maior número de dados e informações sobre esse fruto se faz necessário para melhor compreensão de seu ciclo vegetativo (SOARES et al., 2014).

O cupu (nome utilizado regionalmente) ou cupuaçu (Theobroma grandiflorum) é uma frutífera nativa da região Amazônia, sendo uma das frutas mais populares nessa região com enorme potencial econômico. A polpa corresponde a $35 \%$ da fruta, as cascas $45 \%$, e as sementes a $20 \%$. A parte mais valorizada do fruto é a polpa, utilizada para o consumo de várias formas como: suco, torta, sorvete, creme, 
geleia e outros doces que, na maioria das vezes, são processados e comercializados de forma artesanal. As amêndoas de cupuaçu, subproduto de sua polpa, apresentam grandes possibilidades para as indústrias de fármacos, cosméticos e, principalmente, para a produção cupulate, produto análogo ao chocolate, por não conter em sua composição a cafeína e teobromina, compostos alergênicos e presentes no cacau (HOMMA, 2016).

A produção de cupuaçu no Brasil, considerando os estabelecimentos agropecuários com mais 50 cupuaçuzeiros existentes, está estimada em pouco mais de 24 mil toneladas, dos quais a região Norte contribui com mais de 18 mil toneladas (IBGE, 2018). Silva e Farias (2018) concluíram que utilização da matéria prima agregam valores as frutas da Amazônia, enaltecendo os produtos e subprodutos na região Norte do Brasil, gerando sustentabilidade à região.

Em termos nutricionais, os frutos Amazônicos apresentam uma abundante disponibilidade de proteínas, carboidratos, fibras, vitaminas e minerais, que poderiam viabilizar valores nutricionais para a população. Entretanto, a realidade social, econômica e o quadro de precariedade da saúde e da nutrição registrado na região contrastam, frontalmente, com a sua riqueza em recursos biológicos. Diante dessa biodiversidade frutífera faz-se necessário maior valorização destes frutos ainda pouco caracterizados e explorados por pesquisadores. Maiores informações sobre estas frutas podem ajudar no processo de desenvolvimento de novos produtos para melhoria na alimentação e saúde da população (NEGRI et al., 2016).

O objetivo deste trabalho foi caracterizar físico-quimicamente três frutos nativos da Amazônia Ocidental, quantificando suas biomoléculas e obtendo de tal modo suas características nutricionais.

\section{MATERIAL E MÉTODOS}

O estudo foi realizado no Laboratório de Bromatologia da Universidade Federal do Acre - Campus Floresta, entre os meses de Agosto de 2017 à Junho de 2018. O delineamento experimental utilizado foi o inteiramente casualizado, com três tratamentos (frutos) e quatro repetições. Foi realizada a caracterização físicoquímica de três frutos da Amazônia, sendo eles: Abiu (Pouteria caimito [Ruiz\&Pav]) Radlk), Biribá (Rollinia mucosa [Jacq.])) e Cupuaçu (Theobroma grandiflorum).

O material analisado foi coletado no município de Cruzeiro do Sul - Acre e arredores e encaminhados para o Laboratório de Bromatologia do Campus Floresta, onde foi realizada a seleção dos frutos e preparo para análises. Foram utilizados quatro frutos em estádio completo de maturação.

No preparo das amostras, os frutos foram pesados in natura e em seguida realizou-se a despolpa. A polpa foi pesada e os dados obtidos foram utilizados para a determinação da porcentagem comestível do fruto. A análise bromatológica da polpa dos frutos foi realizada considerando os seguintes parâmetros, de acordo com a metodologia proposta por Silva e Queiroz (2002): Matéria Seca (MS), determinada através da volatilização provocada pelo calor. O percentual de MS é calculado através da diferença do peso da amostra antes e após o tratamento com calor. $\mathrm{Na}$ determinação das Cinzas ou Matéria Mineral (MM), a amostra é incinerada à $500^{\circ} \mathrm{C}$, para eliminação da matéria orgânica. A matéria $A$ matéria inorgânica que não volatiliza nessa temperatura é denominada cinzas.

No Extrato Etéreo (EE) o éter é aquecido e volatilizado e depois, ao condensar-se, passa pela amostra e arrasta as frações solúveis nele. $O$ procedimento é repetido sucessivamente até não restarem mais frações extraíveis 
na amostra. O éter é destilado e coletado em outro recipiente, enquanto a gordura extraída é calculada por diferença de pesagem do balão coletor pelo método de Soxhlet.

Para determinação da Proteína Bruta (PB) o nitrogênio ou proteína e outros compostos são transformados em sulfato de amônio por digestão do ácido sulfúrico fervente. $O$ ácido digerido é resfriado, diluído com água destilada e tornando fortemente alcalino com hidróxido de sódio. A amônia é desprendida e destilada numa solução de ácido bórico. A amônia na solução de ácido bórico é titulada com o ácido clorídrico padronizado. Portanto, busca-se isolar e quantificar o nitrogênio total (N) e estimar o conteúdo protéico através do fator de conversão de cada alimento ou através do fator universal $(6,25)$ pelo método Kjeldahl.

Para a Fibra Bruta (FB) é uma fração dos alimentos composta por carboidrato estrutural, obtida após uma digestão ácida, seguida de uma digestão básica. Uma amostra seca e desengordurada é submetida à digestão com uma solução ácida e depois com uma solução básica fraca. O resíduo orgânico é recebido em cadinho Gooch (Schoot G2 - $50 \mathrm{ml}$ ), sendo queimado em mufla à temperatura de $550^{\circ} \mathrm{C}$. A perda de peso após ignição é denominada de fibra bruta.

Carboidratos Totais ou Extrativo Não-Nitrogenado (ENN), calculados por diferença da matéria seca (MS), fibra bruta (FB), extrato etéreo (EE), proteína bruta (PB) e matéria mineral (MM). Os dados foram submetidos à análise estatística utilizando o software SISVAR (FERREIRA, 2011). Para verificar possíveis diferenças entres as médias obtidas foi aplicado o teste de Tukey ao nível de $5 \%$ de probabilidade.

\section{RESULTADOS E DISCUSSÃO}

Foi observada diferença significativa $(p \leq 0,05)$ para os teores médios em porcentagem das características bromatológicas em todas as variáveis analisadas (Tabela 1).

TABELA 1. Médias percentuais para Matéria seca (MS), Matéria Mineral ( $M M)$ e Proteína Bruta $(\mathrm{PB})$ de frutos nativos no Vale do Juruá - $A C$, com base na matéria seca.

\begin{tabular}{lccc}
\hline Frutos & MS (\%) & MM (\%) & PB (\%) \\
\hline Abiu & $15,25 \mathrm{a}$ & $0,63 \mathrm{~b}$ & $4,36 \mathrm{~b}$ \\
Biribá & $11,81 \mathrm{~b}$ & $0,95 \mathrm{~b}$ & $4,56 \mathrm{~b}$ \\
Cupuaçu & $15,03 \mathrm{a}$ & $1,05 \mathrm{a}$ & $7,03 \mathrm{a}$ \\
\hline CV & 11,10 & 3,78 & 10,03 \\
\hline
\end{tabular}

*médias seguidas de mesma letra não diferem estatisticamente entre si pelo teste de Tukey $(p \leq 0,05)$.

Os teores médios em percentuais de matéria seca variaram de 11,81\% a $15,25 \%$, respectivamente, para os frutos biribá e abiu. Ao analisar as características bromatológicas de polpas de frutos da Amazônia, Canuto et al. (2010), obtiveram teores médios de matéria seca de 4,2 \% para a polpa do abiu, divergindo do valor encontrado no presente estudo.

Quanto a Matéria Mineral, observou-se uma variação de 0,63\% para o abiu com menor nível e 1,05\% para o cupuaçu com maior nível. Ao realizar a caracterização centesimal, microbiológica e sensorial da polpa de cupuaçu, Freire et 
al., (2009), encontraram valores de matéria mineral que variaram de 0,68 a 0,74\%, valores próximos ao encontrado nesse trabalho.

Com relação aos percentuais médios de proteína bruta, o cupuaçu se destacou com 7,03\%, superando os valores dos demais frutos. Gonçalves et al. (2013), ao realizarem a caracterização físico-química e reológicas da polpa de cupuaçu congelada encontraram um valor médio de $7,25 \%$, teores proteicos que corroboram com este trabalho.

Os valores obtidos para à análise bromatológica das polpas do abiu, biribá e cupuaçu quanto ao teor de extrato etéreo, fibra bruta e extrativo não-nitrogenado estão apresentados na Tabela 2.

TABELA 2. Extrato Etéreo (EE), Fibra Bruta (FB) e Extrativo Não-Nitrogenado (ENN) de diferentes frutos cultivados no Vale do Juruá - AC, com base no extrato etéreo.

\begin{tabular}{lccc}
\hline Amostra & EE (\%) & FB (\%) & ENN (\%) \\
\hline Abiu & $3,57 \mathrm{a}$ & $3,55 \mathrm{a}$ & $87,87 \mathrm{a}$ \\
Biribá & $2,70 \mathrm{~b}$ & $3,15 \mathrm{a}$ & $88,62 \mathrm{a}$ \\
Cupuaçu & $3,15 \mathrm{a}$ & $4,79 \mathrm{~b}$ & $83,95 \mathrm{~b}$ \\
\hline CV\% & 1,77 & 0,45 & 1,94 \\
\hline
\end{tabular}

*Médias seguidas de mesma letra não diferem estatisticamente entre si pelo teste de Tukey $(p \leq 0,05)$.

Conforme os dados apresentados na Tabela 2 houve diferença significativa $(p \leq 0,05)$ para as polpas dos frutos apenas na variável Extrativo Não-Nitrogenado. Na variável Extrato Etéreo, os maiores valores médios encontrados foram para o abiu $(3,57 \%)$, e o cupuaçu (3,15\%). Canuto et al., (2010) encontraram teores que variaram de 0,1 a $0,3 \%$ na polpa do abiu e cupuaçu, respectivamente.

Com relação à fibra bruta, notou-se uma variação de $3,15 \%$ para o biribá e 4,79\% para o cupuaçu. Avaliação feita em Brasil, (2015), em alimentos regionais brasileiros, encontrou um valor médio de 0,2\% para o abiu. Mesquita et al. (2014), em estudo da composição centesimal do cupuaçu, e de outros frutos típicos do Vale do Juruá, encontraram um valor médio de fibra bruta de 5,60\%, mostrando que o valor foi superior ao encontrado no presente estudo.

Para o extrativo não-nitrogenado, os frutos apresentaram uma variação de $83,95 \%$ para o cupuaçu a $88,62 \%$ para o biribá. Avaliando a composição centesimal de frutos típicos da região do Vale do Juruá-Amazônia ocidental, Mesquita et al., (2014), encontraram um valor médio de ENN na polpa do cupuaçu de $75,95 \%$, valor inferior ao encontrado no presente estudo.

Mais estudos são necessários para ampliar o conhecimento científico da população do Vale do Juruá, e assim obter a informações dos valores nutricionais das polpas de cada um dos frutos, gerando um incentivo ao consumo de um alimento de fonte natural regional e saudável, de baixo custo que possa garantir benefícios a saúde.

\section{CONCLUSÃO}

As polpas dos frutos avaliados apresentaram composição bromatológica distinta. Os resultados obtidos são relevantes no contexto da região do Vale do Juruá, pois permitem o refinamento das informações nutricionais acerca dessas espécies frutíferas, além de agregar valor e subsidiar estratégias para a elaboração 
e uso dos produtos oriundos das mesmas, seja na dieta humana ou para outras finalidades. O estudo da composição bromatológica dos produtos e subprotudos dos frutos amazônicos é relevante do ponto de vista nutricional, social, cultural e econômico.

\section{REFERÊNCIAS}

ANDRIGUETO, J. R. ; NASSER, L. C. B.; TEIXEIRA, J. M. A. Produção integra de frutas: Conceito, histórico e a evolução para o sistema agropecuário de

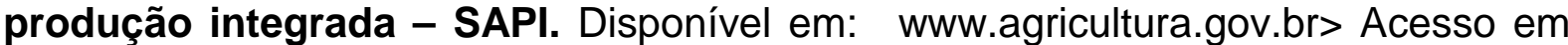
maio 2018.

BRASIL. Ministério da Saúde. Secretaria de Atenção à Saúde. Departamento de Atenção Básica. Alimentos regionais brasileiros / Ministério da Saúde, Secretaria de Atenção à Saúde, Departamento de Atenção Básica. - 2. ed. - Brasília : Ministério da Saúde, 484 p. : il. ISBN 978-85-334-2145-5. 2015.

CANUTO, G. A. B, XAVIER, A. A. O.; NEVES, L. C.; BENASSI, M. T. Caracterização físico-química de polpas de frutos da Amazônia e sua correlação com a atividade anti-radical livre. Revista Brasileira de Fruticultura 32(4): 1196-1205, 2010.

DONADIO, L.C.; MORO, F.V.; SERVIDONE, A.A. Frutas brasileiras. Jaboticabal: FUNEP, 288p. 2002.

FERREIRA, D. F. SISVAR: Sistema de Análise de Variância. Lavras - MG: UFLA, 2011.

GONÇALVES, M. V. V. A.; SILVA, J. P. L.; MATHIAS, S. P.; ROSENTHAL, A.; CALADO, V. M. A. Caracterização físico-química e reológicas da polpa de cupuaçu congelada (Theobroma grandiflorum Schum). Perspectivas online exatas e engenharia. Campos dos Goytacazes, ed. 3, p. 46-53, 2013.

HOMMA, A. K. O. Perspectivas de mercado para as fruteiras nativas amazônicas. 2016. Disponível em: https://www.researchgate.net/publication/311558590_Perspectivas_de_Mercado_par a_as_Fruteiras_Nativas_Amazonicas. Acesso em: 21/09/2018.

IBGE. Sidra/ banco de dados agregados. Disponível em:Shttps://sidra.ibge.gov.br/tabela/6616_resultado>. Acesso em: 21/09/2018.

MESQUITA, F. R.; LIMA, M. O.; ARAÚJO, J. M.; RIBEIRO, O. A. S.; CRAVEIRO, R. L. Composição centesimal de frutos típicos da região do vale do Juruá-Amazônia Ocidental. Enciclopédia Biosfera, Centro Científico Conhecer - Goiânia, v.10, n.19; p.2849-2857, 2014.

NEGRI, T. C.; BERNI, P. R. A.; BRAZACA, S. G. C. Valor nutricional de frutas nativas e exóticas do Brasil. Biosaúde, Londrina, v. 18, n. 2, 2016.

ROMERO, T. Amazônia em pé vale muito mais. Disponível em: $\leq w w w . a m b i e n t e e m f o c o . c o m$. br/?p=5096>. Acesso em: jul. 2009. 
SILVA, A. S. S.; FARIAS, L. F. Elaboração da farinha à base da amêndoa do cupuaçu Theobroma grandiflorum Schum. Revista Arquivos Científicos. Macapá, v. 1, n. 1, p. 36-42, 2018.

SILVA, D. J.; QUEIROZ, A. C. de. Análise de alimentos: métodos químicos e biológicos. 235p. 3.ed. Viçosa: UFV, 2002.

SILVA, F. W. A.; GURGEL, E. S. C.; CRUZ, E. D.; SANTOS, J. U.M. Morfologia do fruto, da semente, da plântula e da planta jovem de Sarcaulus brasiliensis A. DC. Eyma (Sapotaceae). Biota Amazônia. Macapá, v. 6, n. 3, p. 7-11, 2016

SOARES, J. D. R.; DIAS, G. M. G.; RODRIGUES, F. A.; PASQUAL, M.; CHAGAS, E. A. Caracterização anatômica e citométrica em biribazeiro (Rollinia mucosa [Jacq.]). Revista Brasileira de Fruticultura, Jaboticabal, v. 36, n. spe1, p. 272-280, 2014. 